\title{
Lifetime opiate exposure as an independent and interactive cardiovascular risk factor in males: a cross-sectional clinical study
}

This article was published in the following Dove Press journal:

Vascular Health and Risk Management

I October 2013

Number of times this article has been viewed

\section{Albert S Reece \\ Gary K Hulse}

School of Psychiatry and Clinical Neurosciences, University of Western

Australia, Crawley, WA, Australia
Correspondence: Albert S Reece 39 Gladstone Rd, Highgate Hill, Brisbane, QLD 404I, Australia

Tel +6I 738444000

Fax +6I $7384440 I 5$

Email sreece@bigpond.net.au
Introduction: While several studies have identified an increased incidence of cardiovascular disorders in opiate dependence, neither opiates as a cardiovascular risk factor nor their effect on central arterial function has been considered.

Methods: Pulse wave analysis (SphygmoCor, AtCorMedical Pty Limited, Sydney, NSW, Australia) was undertaken on a cohort of controls and opiate dependent patients and the results compared to their lifetime opiate exposure.

Results: Controls ( $\mathrm{N}=401)$ were compared with 465 opiate dependent men. The mean $(\log )$ ages were different and were found to be $28.80 \pm 0.49$ years versus $35.02 \pm 0.39$ years $(P<0.0001)$, respectively. Of the opiate dependent group, $87.7 \%$ were treated with buprenorphine, $8.8 \%$ with methadone, and 3.4\% with naltrexone. Multiple regression analysis was used to adjust for chronologic age (CA). At CA of 60 years, the modeled age in the controls was 66.40 years, and that in the addicted group was 73.11 years, an advancement of 6.71 years, or $10.10 \%$. Exacerbations of age dependent changes in central arterial stiffness, central pressures, pulse rate, ejection duration, diastolic duration, and subendocardial perfusion ratio by opiate dependence were all noted $(P<0.05)$. Current heroin dose, heroin duration, and the dose duration interaction were all significantly related to the vascular (or "reference") age (RA)/CA ratio (all $P<0.006$ ). After multivariate adjustment, the opiate dose duration was independently predictive of RA $(P<0.02)$. Opiate dose and/or duration were included in a further 25 terms.

Conclusion: These data show that opiate use is not benign for the male cardiovascular system, but has a dose response relationship to central arterial stiffness and thus cardiovascular aging, acting independently and interactively with established cardiovascular risk factors. These findings imply accelerated organismal aging.

Keywords: arterial stiffness, heroin, opiate dependence, vascular aging, human aging, methadone

\section{Introduction}

While drug addiction in general, and opiate addiction in particular, have long been associated in the popular mind and the professional literature ${ }^{1,2}$ with poor health, the pervasive perception remains that pure opiates themselves are relatively innocuous to health, even in the long-term. ${ }^{3-7}$ This is in contradistinction to stimulant abuse where cardiovascular toxicity is well known and widely appreciated. ${ }^{3}$ If this widespread presumption relating to opiates is not correct, it carries obvious cautionary implications for niche areas of medical practice within the management of drug dependence, such as indefinite maintenance with full opiate agonist agents such as methadone and levoacetyl $\alpha$-methadol, and medical trials of long-term heroin maintenance. However, this benign 
presumption also carries widespread implications beyond the management of drug abuse and dependency for at least two reasons.

Firstly, a significant amount of literature dating back at least 40 years has indicated that some of the most important effects of opiates relate to their effects on tissue growth. ${ }^{8}$ It has been definitively and repeatedly shown that there is a constitutive inhibitory effect on tissue trophism maintained by opioidergic tone mediated mainly by $\beta$-endorphin and met-enkephalin. This can be pharmacologically uncovered with antagonists such as naloxone and naltrexone. It has been shown to be of a magnitude of about $-30 \%{ }^{8,9}$ Similarly, the administration of opiates to young growing animals can inhibit the growth of all their organs and their body overall. The effect is again about $+30 \%{ }^{9}$ This information is being used to plan and develop treatments for malignancy and for the healing of corneal ulcers. ${ }^{8,9}$ The effect has been shown to be due to a special perinuclear receptor for met-enkephalin, called the opiate growth factor receptor. This receptor has been cloned and sequenced, and its gene identified. ${ }^{9}$ This process can be blocked with designed siRNAs for the receptor gene. ${ }^{9}$ Importantly, this ligated receptor has been shown to act through P16 inhibitor of cyclin dependent kinase 4A (P16INK4A) and P21 cyclin dependent kinase inhibitor 1A (P21WAV1/CIP1) to block cyclin dependent kinases 4 and 6 of the cell cycle. ${ }^{10}$ The identification of the short arm of chromosome 9p21 in many genome wide association studies (GWAS) as being a hot spot for coronary artery disease association, notwithstanding that the actual locus has been described as a "gene desert" for protein coding genes, is now well known. ${ }^{11,12}$ Cyclin-dependent kinase inhibitor $2 A(C D K N 2 A)$, the gene which transcribes P16INK4A is nearby this locus, and interactions have been defined between a long nonprotein coding RNA, known as anti-sense non-coding RNA in the INK4 locus (ANRIL), which occupies the site identified by GWAS, and the promoter of $C D K N 2 A$ via a cis-acting mechanism ${ }^{13}$ in addition to other pathways. ${ }^{14,15}$ This locus also codes for P15INK4B and P19ARF, which are associated with inhibition of cell growth and the induction and maintenance of tissue senescence. Because P14, P15, P16, and ANRIL are associated with senescence, 9p21.3 has been designated the "senescence locus." Hence, clinical opiate dependence and its manipulation may provide a unique window into the operation of this system.

Secondly, opiate dependence may arise by several clinical pathways in addition to drug abuse per se, particularly by the management of chronic pain and iatrogenic routes. In the US, chronic pain accounts for $21 \%$ of emergency room (ER) visits, $25 \%$ of work days missed, and over $\$ 100$ billion in health expenditure. ${ }^{16}$ It is a condition affecting one third of Americans in their lifetime. ${ }^{16}$ The Drug Abuse Warning Network has shown that four of the top ten drugs involved in ER visits are the opiates oxycodone, vicodin, methadone, and other opiates. ${ }^{17}$ This dataset also shows a rise in non methadone non heroin opiate overdoses from $2.2 \%$ of all ER visits in 1997 to $11.5 \%$ in $2009 .{ }^{17}$

Pulse wave analysis (PWA) by radial arterial tonometry is a technique which has been widely applied to many clinical conditions which affect the vasculature either primarily or secondarily. ${ }^{18-21}$ It has the major advantage of being sensitive to changes in arterial stiffness in the third and fourth decade of life, a period before many other techniques for measuring arterial function become usefully discriminatory. PWA is performed by taking a sensitive pressure recording of the radial arterial waveform over the wrist, and back calculating from it to derive a central pressure waveform in the aortic root and central large arteries using a validated transfer function, calibrated by the brachial blood pressure. The central waveform is a combination of the forward moving incident pressure wave from the heart together with the reflected backward directed waveform from resistance sites in the periphery. Dedifferentiation and deconvolution allow the two wave forms to be distinguished from each other. The amplitude and speed of the reflected wave is a direct function of the stiffness of the arterial tree, and therefore, an age related measure of arterial function. This "augmentation" of the incident cardiac pressure by the reflected wave is known as the central augmented pressure. Its ratio with the pulse height is defined as the central augmentation index. From these data a vascular (or "reference") age can be calculated automatically by the SphygmoCor software system (AtCorMedical Pty Limited). as these measurements have been calibrated with age in reference populations. They are affected by certain variables such as heart rate and height. Both the central augmentation pressure and index are corrected to a pulse rate of 75 to adjust for the effect of the pulse frequency. The vascular reference age is based on the corrected augmentation index adjusted for height and sex.

Finally, the point has been well made that since over half the population in Western nations die from cardiovascular causes, at least half of the effect of aging may be attributed to cardiovascular disease. ${ }^{22}$ For this reason, the importance of these results extends beyond the cardiovascular system, in that by quantifying arterial stiffness and deriving a cardiovascular age, the technique is effectively constructing 
a surrogate marker for the biological age for the whole organism.

In summary, the conceptual framework of the present study is that opiates are related to senescence induction, stem cell inhibition, and immune stimulation (discussed further below) which together lay the foundation for a progeroid underlying pathophysiological state which forms the backdrop and proximal causal milieu for the myriad of observed pathologies. Vascular aging is expected to occur as part of organism aging, and is an important surrogate biomarker of the aging process in the whole organism. These considerations lead to the following hypotheses: (1) that opiate exposed patients may demonstrate increased cardiovascular age, and that (2) a dose response relationship may exist which is independent of, and in addition to, and/or interactively compounds, known cardiovascular risk factors. The present work tests these hypotheses in a clinical sample of men. As Southcity Family Medical Centre, Highgate Hill, Brisbane, QLD, Australia, sees both opiate dependent and general medical patients and has expertise in the technique of PWA, this site formed an ideal location to test the purported benignity of opiates on the cardiovascular system empirically. Companion papers address this subject in females ${ }^{23}$ by various pharmacotherapy types, ${ }^{24}$ and also consider the case when opiate agonism is replaced by antagonist-induced sobriety. ${ }^{25}$

\section{Methods}

\section{Patient selection and treatment}

Control subjects were taken from patients presenting for employment or insurance medical examinations, patients with minor health problems such as ear blockages, or patients presenting with minor psychological issues. University students were also sampled. Patients presenting in the course of their normal buprenorphine or methadone treatment were sampled at the time of their visit. Their treatment was in accordance with established therapeutic guidelines. Patients who had been treated by naltrexone implantation were also sampled opportunistically on the occasion of their clinic visit. Patients did not have naltrexone implants inserted as part of this study. Naltrexone implants were $1.7 \mathrm{~g}$, derived from Go Medical Industries (Perth, WA, Australia) and designed to last for 5 months. Naltrexone implants are not a registered therapeutic good in Australia, but are available to patients under the compassionate access scheme within the Special Access Scheme of the Therapeutic Goods Administration in Canberra, ACT, Australia. These procedures have previously been described in detail. ${ }^{26}$ The study was performed from 2006 to 2011.

\section{PWA measurements}

Patients were recumbent for 5 minutes prior to pressure recording. Sleeping and talking were not permitted during the studies, but prior eating, drinking, and alcohol and tobacco consumption were not restricted. Where it became clear that alcohol had been recently consumed, the studies of that day were omitted. PWA was performed using the technique of SphygmoCor, the Miller microtonometer, and the AtCor preamplifier and hardware, all obtained from AtCorMedical Pty Limited. Parameters were generated automatically by the software. PWA was measured over the right radial artery unless it was unavailable. The brachial blood pressure was measured in the contralateral arm with an Omron HEM 907 oscillometric device (Omron Corporation, Kyoto, Japan). All measurements were taken in quintuplicate wherever possible. Notes were taken at the time of the study relating to the patients' recent drug use, and entered into the software database. Patients whose main opiate of abuse was not heroin had their medication converted into oral morphine equivalents, and then into street heroin equivalents at the rate of $500 \mathrm{mg}$ of morphine per gram of street heroin. The heroin dose entered was the usual daily dose injected at the time of the PWA study.

Major indices calculated from this technique included the vascular or reference age (VA and RA, respectively), the chronologic age (CA), the central augmentation pressure at heart rate 75 , the central augmentation pressure/pulse height ratio at heart rate 75 which is also known as the augmentation index, peripheral-central pulse pressure amplification ratio, central pulse height, central systolic pressure, central diastolic pressure, central mean pressure, central end systolic pressure, central diastolic time index (C_DTI), central tension time index (C_TTI), central diastolic duration, an index of subendocardial perfusion known as the subendocardial perfusion ratio, central stroke volume index or the Buckberg ratio, which is defined as the $\mathrm{C}_{-} \mathrm{TTI} / \mathrm{C}$ _DTI.

\section{Statistics}

Data are listed as mean \pm standard error of the mean (SEM). Categorical variables were compared in EpiInfo version 7.0.8.3 from CDC (Atlanta, GA, USA). Data were log transformed to comply with normality assumptions. Arcsinh is a transformation similar to the log transformation, and also accepts negative and zero arguments. C-reactive protein (CRP) was arcsinh transformed in all multiple regression 
studies. Continuous statistics were compared in a bivariate manner in Statistica version 7.1 from Statsoft, Inc., (Tulsa, OK, USA). Where Levene's test was significant, $t$-tests were performed with separate variances. Adjustment for multiple testing in bivariate comparisons was not performed as this was not the primary focus of the analysis. It is not appropriate to the limited number of multiple regressions employed. Multiple linear regression was performed in " $\mathrm{R}$ " version 2.13.1, downloaded from the Central "R" Archive Mirror (University of Melbourne, Melbourne, VIC, Australia). Model appropriateness and maximization was done using ANOVA tests and the Akaike information criterion (AIC). Graphs were drawn using Ggplot2 software (Hadley Wickham, Houston, TX, USA). $P<0.05$ was considered significant.

\section{Ethical approval}

All patients gave informed consent prior to any of the study procedures being undertaken. Patients having naltrexone implants also gave informed written consent. The study was approved by the Human Research Ethics Committee of the Southcity Family Medical Centre (Highgate Hill, QLD, Brisbane Australia), which has been approved by the National Health and Medical Research Council (Australia). All procedures and investigations were in accordance with the Declaration of Helsinki for research subjects. Compliance was maintained throughout with all applicable regulatory requirements.

\section{Results}

\section{Sociodemographic data}

As shown in Table 1, 401 controls were compared with 465 patients with opiate dependence, a total of 866 male patients. Table 1 also gives biometric, substance use, and various laboratory values for the two groups.

Significant differences in CA were noted with the mean \pm SEM being $28.80 \pm 0.49$ years and $35.02 \pm 0.39$ years in the control and opiate dependent groups, respectively (log comparison $\mathrm{t}=11.7443, d f=786.69, P<0.0001)$. Substance use and some laboratory parameters were also noted as significantly different. These latter parameters have been previously reported. ${ }^{27}$ Of the opiate dependent patients, $408(87.74 \%)$ were treated with buprenorphine, $41(8.82 \%)$ with methadone, and $16(3.44 \%)$ with naltrexone. The mean dose of buprenorphine was $7.05 \pm 0.29 \mathrm{mg}$, and the mean dose of methadone was $68.04 \pm 5.27 \mathrm{mg}$.

\section{Bivariate PWA data}

Comparative central and peripheral cardiovascular parameters are presented in Table 2. The VA and measures of
Table I Sociodemographic parameters

\begin{tabular}{|c|c|c|c|}
\hline Parameter & Controls & $\begin{array}{l}\text { Opiate } \\
\text { dependence }\end{array}$ & $P$-value \\
\hline No & 401 & 465 & \\
\hline \multicolumn{4}{|l|}{ Biometrics } \\
\hline Chronologic age (CA)* & $28.80(0.49)$ & $35.02(0.39)$ & 0.0000 \\
\hline Height (m) & $177.0(0.4)$ & $177.3(0.3)$ & 0.5303 \\
\hline Weight (kg) & $76.19(0.6)$ & $80.23(0.7)$ & 0.0001 \\
\hline BMI $\left(\mathrm{kg} / \mathrm{m}^{2}\right)$ & $24.28(0.19)$ & $25.49(0.21)$ & 0.0000 \\
\hline \multicolumn{4}{|l|}{ Substance abuse } \\
\hline Smokers, No (\%) & $63(|5.7| \%)$ & $434(93.33 \%)$ & 0.0000 \\
\hline Cigarettes/day & $\mathrm{I} .6(0.2)$ & $17.6(0.5)$ & 0.0000 \\
\hline Minutes post cigarette & II $4.6(7.9)$ & $91.6(16.6)$ & 0.2106 \\
\hline Heroin dose $(\mathrm{g})$ & $0(0)$ & $0.5 I(0.02)$ & 0.0000 \\
\hline Heroin duration (yrs) & $0.08(0.05)$ & $13.48(0.39)$ & 0.0000 \\
\hline Heroin dose duration ( $g$-yrs) & $0.04(0.02)$ & $7.34(0.42)$ & 0.0000 \\
\hline \multicolumn{4}{|l|}{ Laboratory values } \\
\hline Cholesterol (mmol/L) & $4.82(0.13)$ & $4.4 \mid(0.05)$ & 0.0013 \\
\hline Triglyceride $(\mathrm{mmol} / \mathrm{L})$ & $1.64(0.12)$ & $1.45(0.05)$ & 0.1272 \\
\hline $\mathrm{HDL}$ (mmol/L) & $1.19(0.04)$ & I.I8 (0.02) & 0.8689 \\
\hline LDL (mmol/L) & $3.00(0.15)$ & $2.43(0.05)$ & 0.0005 \\
\hline ALT (IU/L) & $38.36(3.45)$ & $70.55(4.77)$ & 0.0000 \\
\hline AST (IU/L) & $35.69(6.97)$ & $48.76(2.14)$ & 0.0757 \\
\hline Glucose (mmol/L) & $5.28(0.25)$ & $5.59(0.28)$ & 0.5870 \\
\hline Creatinine $(\mathrm{mcmol} / \mathrm{L})$ & $84.87(\mathrm{I} .7 \mathrm{I})$ & $83.98(0.8)$ & 0.6238 \\
\hline Urea (mmol/L) & $5.4(0.13)$ & $5.4(0.3)$ & 0.9218 \\
\hline Albumin (g/L) & $44.19(0.52)$ & $43.65(0.27)$ & 0.3759 \\
\hline Globulin (g/L) & $28.87(0.34)$ & $31.51(0.25)$ & 0.0000 \\
\hline CRP (mg/L) & $3.96(1.05)$ & $6.28(0.52)$ & 0.0475 \\
\hline $\operatorname{ESR}(\mathrm{mm} / \mathrm{hr})$ & $6.86(0.8 I)$ & II.44 (0.54) & 0.0000 \\
\hline Lymphocytes $\left(\times 10^{-9} / \mathrm{L}\right)$ & $2.27(0.08)$ & $2.58(0.05)$ & 0.0095 \\
\hline Monocytes $\left(\times 10^{-9} / \mathrm{L}\right)$ & $0.60(0.03)$ & $0.66(0.02)$ & 0.0636 \\
\hline
\end{tabular}

Notes: Data are reported as mean ( \pm SEM). * denotes statistics for log transformed data.

Abbreviations: ALT, alanine aminotransferase; AST, aspartate aminotransferase; CRP, C-reactive protein; ESR, erthyrocyte sedimentation rate; $\mathrm{HDL}$, high density lipoprotein; LDL, low density lipoprotein; BMI, body mass index; SEM, standard error of the mean.

arterial stiffness are noted to be higher in the substance use disorder (SUD) group in accordance with their higher CA.

\section{Multivariate age data}

Figures 1 to 4 show graphs of various indices of arterial age, stiffness, pressure, and timing, respectively. Significant and interesting differences by opiate dependence status are presented in Table 3 as various parameters regressed against age and addictive status in additive and interactive models. The term "opiate status" in the table refers to the opiate dependent status compared to the control status. The first two rows in this table show that the age and pulse corrected central augmentation pressure $\left(P=7.37 \times 10^{-13}\right)$ and index $\left(P=4.85 \times 10^{-13}\right)$ are both significantly related to the addictive status. The opiate dependency status did not significantly affect the (log) RA either as a factor (est $=0.25, \mathrm{SEM}=0.30$, $P=0.39)$, nor in interaction with $(\log ) \mathrm{CA}(\mathrm{est}=0.07$, $\mathrm{SEM}=0.09, P=0.38$; model adjusted $R^{2}=0.39, F=189.5$, $\left.d f=3,862, P<2.2 \times 10^{-16}\right)$. 
Table 2 Selected cardiovascular parameters

\begin{tabular}{|c|c|c|c|}
\hline Parameter & Controls & $\begin{array}{l}\text { Opiate } \\
\text { dependence }\end{array}$ & $P$-value \\
\hline Operator index & $89.61(0.28)$ & $88.93(0.29)$ & 0.0909 \\
\hline \multicolumn{4}{|l|}{ Ages } \\
\hline Vascular age $(\mathrm{RA})^{*}$ & $31.49(0.76)$ & $39.03(0.83)$ & 0.0000 \\
\hline Difference (RA-CA) & $2.7(0.54)$ & $4.01(0.69)$ & 0.1335 \\
\hline $\mathrm{RA} / \mathrm{CA}$ & $1.10(0.02)$ & I.II (0.02) & 0.5363 \\
\hline $\log (\mathrm{RA} / \mathrm{CA})$ & $0.05(0.01)$ & $0.04(0.02)$ & 0.7884 \\
\hline \multicolumn{4}{|l|}{ Arterial stiffness } \\
\hline C_AP_HR75 & $0.79(0.23)$ & $2.97(0.21)$ & 0.0000 \\
\hline C_AGPH_HR75 & $1.78(0.59)$ & $7.48(0.52)$ & 0.0000 \\
\hline C_PH $(\overline{m m H g})$ & $36.08(0.32)$ & $38.1(0.33)$ & 0.0000 \\
\hline PPAmpRatio & $160.18(0.85)$ & $153.88(0.84)$ & 0.0000 \\
\hline P_Al & $51.88(0.82)$ & $58.98(0.77)$ & 0.0000 \\
\hline \multicolumn{4}{|l|}{ Timing } \\
\hline $\mathrm{HR}$ (bpm) & $69.19(0.58)$ & $69.68(0.58)$ & 0.5518 \\
\hline $\begin{array}{l}\text { Ejection duration } \\
\text { (msec) }\end{array}$ & $321.99(0.99)$ & $322.18(1.02)$ & 0.8917 \\
\hline C_sVI & | 46.28 (I.58) & 144.12 (I.42) & 0.3089 \\
\hline C_DTI & $3,032.5$ (19.57) & $3,048.32(19.37)$ & 0.5675 \\
\hline C_TTI & $2,140.86(\mid 8.56)$ & $2,184.85(19.13)$ & 0.1019 \\
\hline C_Diastolic & $571.16(6.87)$ & $567.85(6.65)$ & 0.7299 \\
\hline \multicolumn{4}{|l|}{ Duration (msec) } \\
\hline \multicolumn{4}{|l|}{ Pressures } \\
\hline SP & $\mathrm{I} 25.56(0.5 \mathrm{I})$ & $|26.2|(0.62)$ & 0.4155 \\
\hline DP & $68.4 I(0.44)$ & $68.26(0.47)$ & 0.8222 \\
\hline Central_SP & $105.74(0.5 \mathrm{I})$ & $107.83(0.56)$ & 0.0055 \\
\hline Central_DP & $69.74(0.45)$ & $69.78(0.48)$ & 0.9510 \\
\hline Central_ESP & $92.66(0.55)$ & $94.74(0.56)$ & 0.0079 \\
\hline Central_MEANP & $86.31(0.46)$ & $87.29(0.5)$ & 0.1450 \\
\hline
\end{tabular}

Notes: Data are reported as mean ( \pm SEM). $*$ denotes statistics for log transformed data.

Abbreviations: bpm, beats per minute; $C A$, chronologic age; $R A$, vascular reference age; C_AP_HR75, central augmented pressure at heart rate 75 bpm; C_AGPH HR75, central augmented pressure/pulse height ratio at heart rate 75 bpm; $C_{-} P H$, central pulse height; PPAmpRatio, peripheral pulse pressure amplification ratio; P_Al, peripheral augmentation index; HR, heart rate; C_SVI, central stroke volume index (Buckberg ratio); C DTI, central diastolic time index; C TTI, central tension time index; SP, systolic pressure; DP, diastolic pressure; ESP, end systolic pressure; MEANP, mean pressure; SEM, standard error of the mean.

\section{Modeled ages}

In terms of minimizing the AIC, the best model for modeling age related change in RA is the semilog model of $\log$ (RA) against $\mathrm{CA}$. The modeled age predicted for the control group at 60 years (intercept $=2.4971$, slope $=0.02831$ ) was 66.40 years, and for the opiate dependent group (intercept $=2.5669$, slope $=0.02875)$ it was 73.11 years, a rise of 6.71 years or $10.10 \%$.

\section{Dose response relationship}

The next matter to be considered was whether there was a dose response relationship between CA corrected $(\log )$ RA and the dose and duration of heroin use in terms of lifetime exposure in opiate exposed patients. When heroin dose and duration were regressed against $(\log ) \mathrm{RA} / \mathrm{CA}$ in an additive model, both were significant (est $=0.1297 \pm 0.0433$ and $-0.0042 \pm 0.0015, P=0.0028$ and 0.0064, respectively; model adjusted $R^{2}=0.0097$; $F=5.177, d f=2,847, P=0.0058)$. When the exercise was repeated in an interactive model, both the heroin duration and the heroin dose:duration interaction were significant (est $=-0.0078 \pm 0.0020,0.0123 \pm 0.0031, P=0.00013$ and 0.000081, respectively; model adjusted $R^{2}=0.0175$, $F=8.544, d f=2,847, P=0.00021)$.

\section{Multivariate assessment of risk factors}

Having determined that a dose response relationship existed between the rise in the RA/CA ratio and lifetime opiate exposure, the final question to be considered was whether such a relationship persisted after adjustment for other known cardiovascular risk factors in opiate exposed patients. Table 4 presents the final model obtained when $(\log )$ RA was regressed against interactive terms in $\mathrm{CA}$, heroin dose, heroin duration, cigarette consumption, high-density lipoprotein (HDL), and CRP, and additive terms in body mass index (BMI), brachial systolic pressure, cholesterol, and height. The time elapsed since the last cigarette was not entered into this model as it was not found to be significant in exploratory modeling. The output has been arranged in ascending order of $P$-values. The model parameters were adjusted $R^{2}=0.4727$, $F=8.225, d f=34,240$, and $P<2.0 \times 10^{-16}$. Interestingly, the heroin dose:duration interaction appears in nine terms (variables or interactions) in this final model. The value of the first interaction is $t=5.014(P=0.000001)$. The dose duration itself appears independently $t=-2.424(P=0.0161)$. The heroin dose or duration appears by themselves in a further 17 terms. Interactive terms involving cigarette consumption, age, HDL, and CRP also feature prominently. CA, tobacco, HDL, and height are independently predictive.

\section{Discussion}

These results show that lifetime opiate exposure significantly affects vascular stiffness, including a significant dose response relationship. The final full multivariate model for VA, which includes the CA, accounts for $47.27 \%$ of the variance. In this model, the opiate dose duration interaction is independently predictive of the VA $(P=0.016)$. Moreover, this interaction occurs another eight times in the model with the most significant $P$-value being $10^{-6}$ (Table 4 ). The opiate dose or duration also occurs another 17 times in a model which is fully adjusted for all other major cardiovascular risk factors including cigarette consumption, systolic blood pressure, cholesterol, HDL, CRP, height, and BMI. The age 


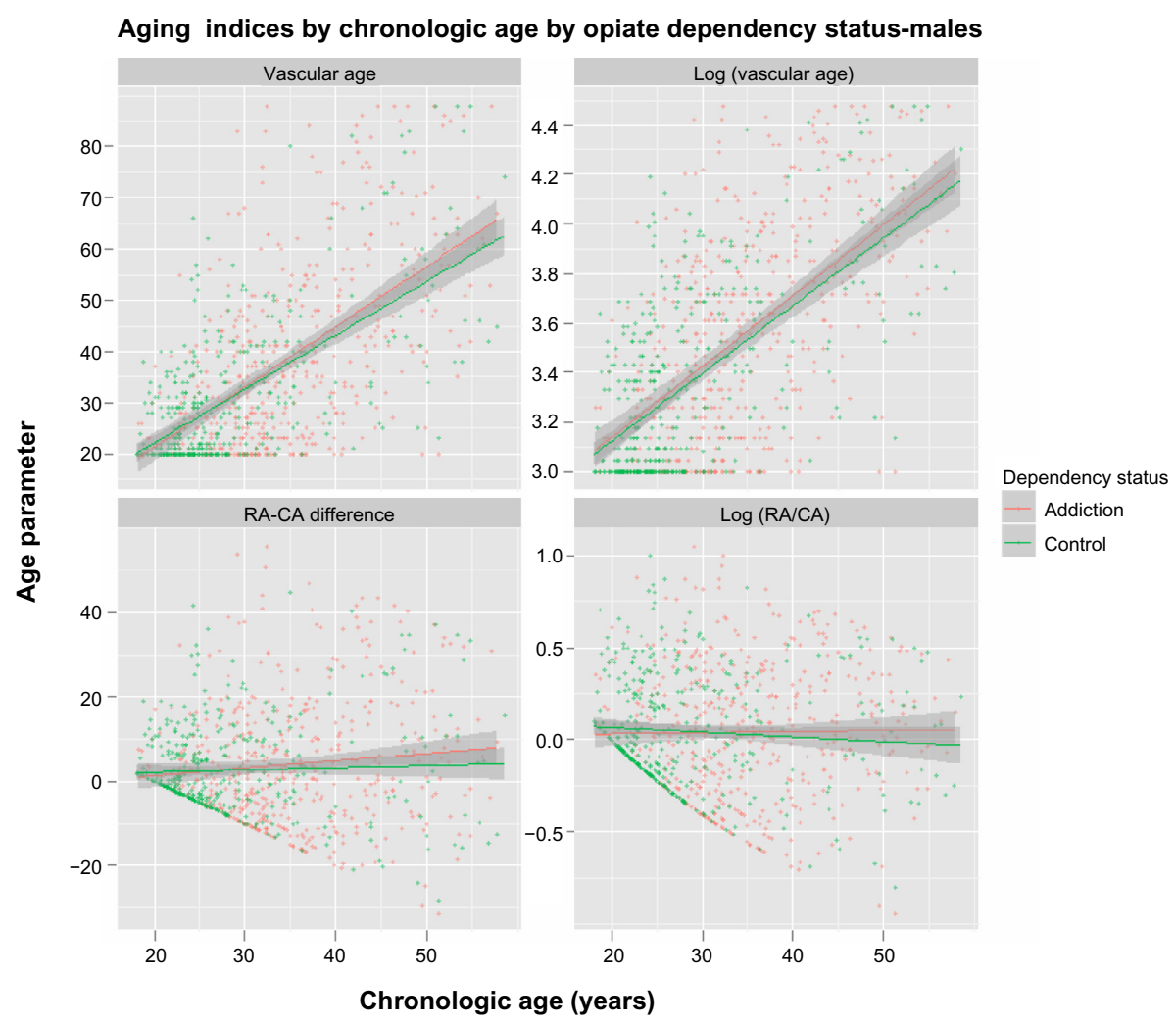

Figure I Aging indices by chronologic age by opiate dependency status.

Abbreviations: CA, chronologic age; RA, reference age.

Arterial stiffness indices by chronologic age by opiate dependency status-males

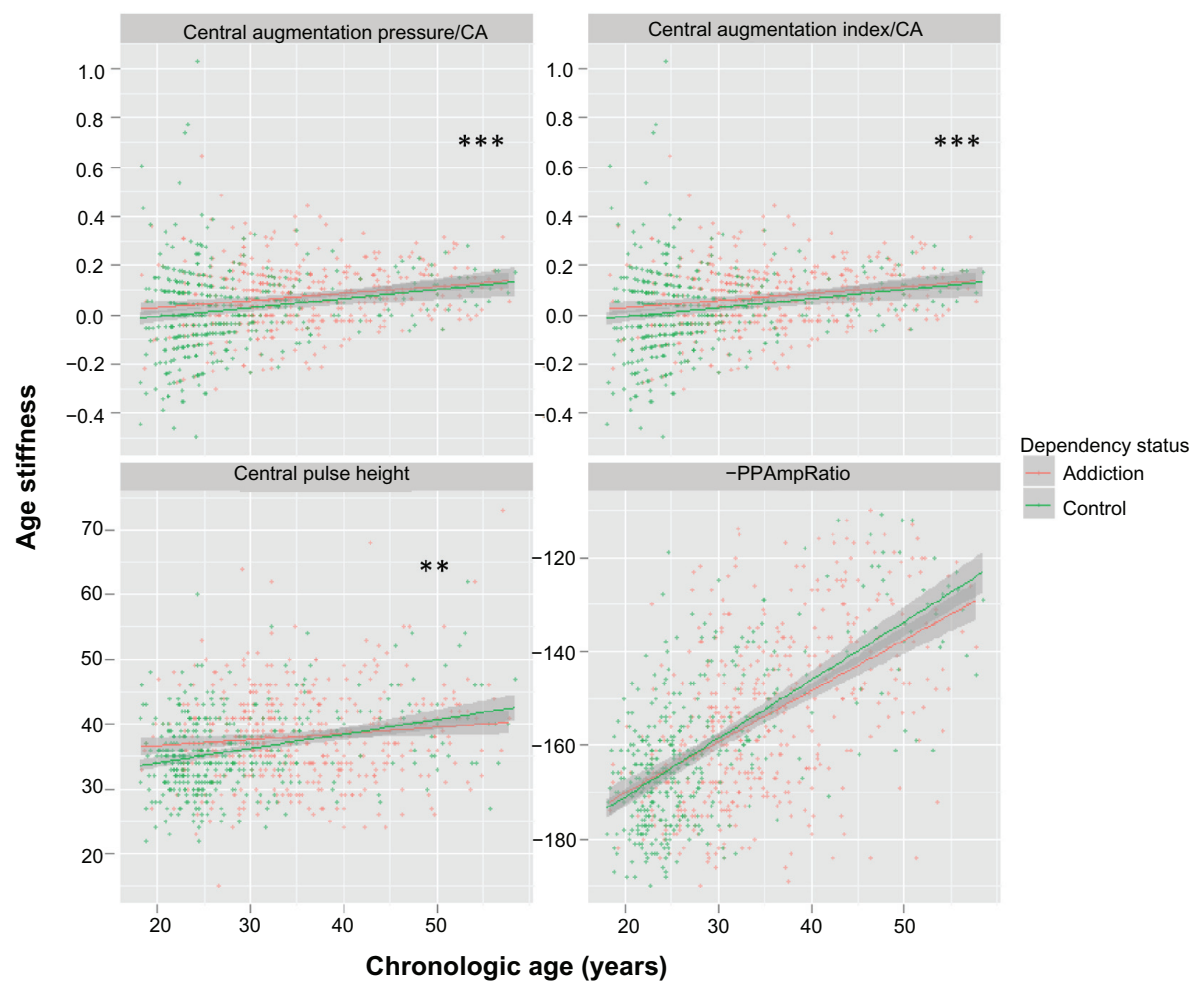

Figure 2 Arterial stiffness by chronologic age by opiate dependency status.

Notes: *** denotes $P<0.0001$ and $* *$ denotes $P<0.005$.

Abbreviations: CA, chronologic age; PPAmpRatio, peripheral pulse pressure amplification ratio. 


\section{Central pressure indices by chronologic age by opiate dependency status-males}

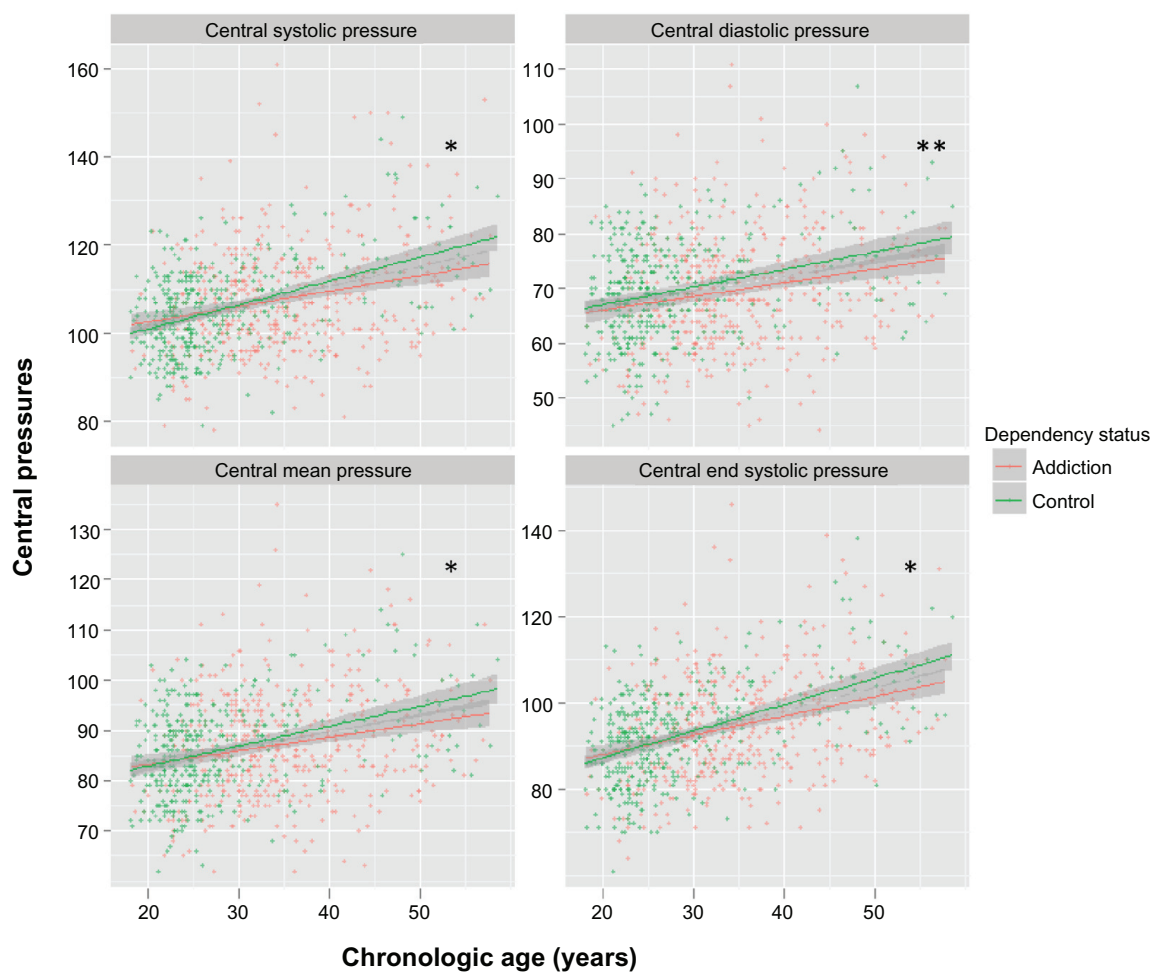

Figure 3 Central pressures by chronologic age by opiate dependency status.

Notes: * denotes $P<0.05$ and $* *$ denotes $P<0.01$. Significance results for central mean and end systolic pressures relate to chronologic age: opiate status interaction.

\section{Central timing indices by chronologic age by opiate dependency status-males}

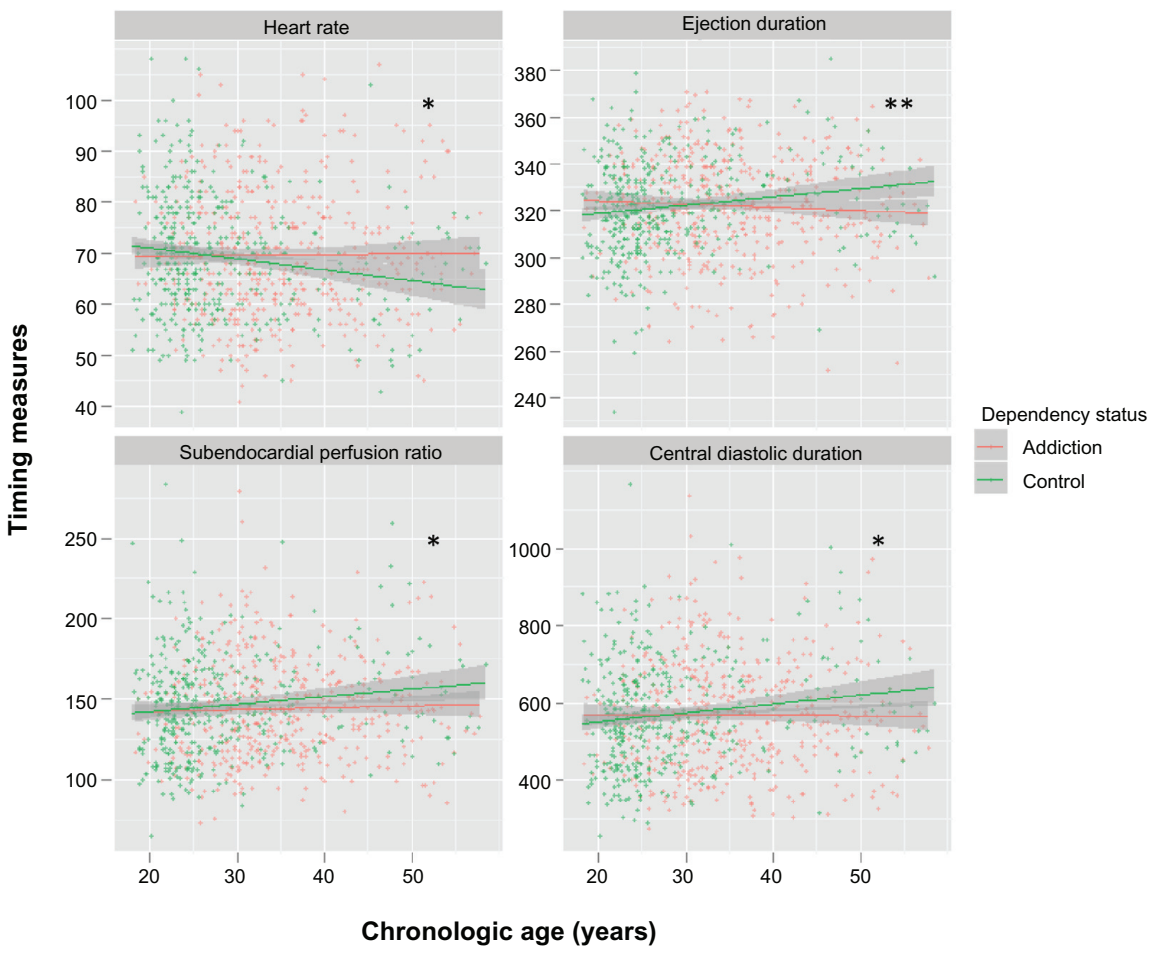

Figure 4 Central timing indices by chronologic age by opiate dependency status.

Notes: * denotes $P<0.05$ and ** denotes $P<0.01$. Significance result indicated for central diastolic duration relates to age: addictive status interaction. 
Table 3 Age dependent multiple regression of central cardiovascular parameters

\begin{tabular}{|c|c|c|c|c|c|c|c|c|}
\hline Parameter & Variable & $\begin{array}{l}\text { Estimate } \\
\text { (SE) }\end{array}$ & t-value & $P(>t)$ & Adjusted $R^{2}$ & F-value & $d f 1, d f 2$ & $\begin{array}{l}\text { Model } \\
P \text {-value }\end{array}$ \\
\hline C_AP_HR75/CA & Opiate.Status & $0.068 \mathrm{I}(0.0093)$ & 7.283 & 0.0000 & 0.0568 & 53.04 & 1,863 & $7.4 \times 10^{-13}$ \\
\hline C_AGPH_HR75/CA & Opiate.Status & $0.1805(0.0246)$ & 7.343 & 0.0000 & 0.0577 & 53.91 & 1,863 & $4.8 \times 10^{-13}$ \\
\hline C_SP & Opiate.Status & $5.32 I I(2.6 I 7 I)$ & 2.033 & 0.0423 & $0.142 \mid$ & 48.75 & 3,862 & $<2.0 \times 10^{-16}$ \\
\hline C_SP & CA:Opiate.Status & $-0.1872(0.078 \mathrm{I})$ & -2.396 & 0.0168 & $0.142 \mid$ & 48.75 & 3,862 & $<2.0 \times 10^{-16}$ \\
\hline C_SVI & CA:Opiate.Status & $-0.1324(0.0666)$ & -1.989 & 0.0470 & 0.0062 & 3.71 & 2,863 & 0.0250 \\
\hline HR & Opiate.Status & $-0.3307(0.1543)$ & -2.144 & 0.0323 & 0.0097 & 3.819 & 3,862 & 0.0097 \\
\hline HR & CA:Opiate.Status & $0.10125(0.0448)$ & 2.259 & 0.0241 & 0.0097 & 3.819 & 3,862 & 0.0097 \\
\hline ED & Opiate.Status & $57.386(18.774)$ & 3.057 & 0.0023 & 0.0110 & 4.219 & 3,862 & 0.0057 \\
\hline ED & CA:Opiate.Status & $-16.956(5.453)$ & -3.109 & 0.0019 & 0.0110 & 4.219 & 3,862 & 0.0057 \\
\hline C_DD & Opiate.Status & 236.55 (I26.28) & 1.873 & 0.0614 & 0.0076 & 3.206 & 3,862 & 0.0226 \\
\hline C_DD & CA:Opiate.Status & $-72.56(36.68)$ & -1.978 & 0.0482 & 0.0076 & 3.206 & 3,862 & 0.0226 \\
\hline C_DP & Opiate.Status & $-1.9297(0.6925)$ & -2.787 & 0.0054 & 0.0604 & 28.78 & 2,863 & $7.98 \times 10^{-13}$ \\
\hline C_DP & CA:Opiate.Status & $-0.563 \mathrm{I}(0.201 \mathrm{I})$ & -2.8 & 0.0052 & 0.0604 & 28.82 & 2,863 & $7.69 \times 10^{-13}$ \\
\hline
\end{tabular}

Abbreviations: CA, chronologic age; C_AP_HR75, central augmented pressure at heart rate 75cbpm; C_AGPH_HR75, central augmented pressure/pulse height ratio at heart rate 75 bpm; C_SVI, central stroke volume index (Buckberg ratio); HR, heart rate; C_DD, central diastolic duration; C_DP, central diastolic presure; C_SP, central systolic pressure; ED, ejection duration; $d f$, degrees of freedom; SEM, standard error of the mean.

and heart rate corrected central augmentation pressure and augmentation index were also shown to be impacted by the addictive status $\left(P<10^{-12}\right)$, as were other major central cardiovascular parameters such as central systolic and diastolic pressures, subendocardial perfusion, heart rate, ejection duration, and diastolic duration. At a modeled CA of 60 years, the predicted VA for the controls was 66.40 years, and for opiate dependent patients, it was 73.11 years. This represents an age advancement of 6.7 years, or $10.10 \%$.

Notwithstanding these clearly deleterious changes in many central hemodynamic parameters, the VA was not shown to be worse in the opiate dependent group, despite the strong dose response relationship. The VA is based on the central augmentation index corrected for height, heart rate, and sex. The augmentation index itself was shown to be related to age in a curvilinear convex upward manner. The pulse rate corrected augmentation pressure was shown to be related in a direct linear manner to CA. Hence, the demonstration that both the central augmentation pressure and index are different in opiate dependence establishes the hypothesis that opiate dependence is associated with cardiovascular aging, despite the failure of the RA itself to reflect such a change.

Furthermore, it is likely that the failure to document an increased RA amongst the substance dependent patients is related to lack of homogeneity within the opiate dependent group. It was noted that $87.7 \%$ of opiate dependent patients in this group were treated with buprenorphine at the unusually low mean dose of $7.05 \pm 0.29 \mathrm{mg}$. Recent evidence suggests that the treatment pharmacotherapy was also a significant determinant of the cardiovascular parameters observed, ${ }^{24}$ and had the group been made up of more patients treated with full opiate agonists such as methadone, as may be common in most cohorts, the central VA would indeed have been relatively elevated. These results, therefore, can be seen as representing a "best case scenario" for opiate dependence because the major treatment employed was probably the mildest of all the available possibilities. This finding, therefore, is not felt to detract significantly from the overall results of the present study.

These results are important because it is not uncommon for studies of cardiovascular pathology to ascribe the observed differences to an increased rate of known high risk lifestyle factors in opiate dependence rather than to the opiates themselves. 4,6,28,29 The models presented herein make full sex specific adjustment for all major cardiovascular risk factors, and demonstrate that significant risk is still attached to lifetime opiate exposure, albeit much of that risk is mediated by its interaction with other known cardiovascular risk factors. It is also important to underscore that it is simplistic to suppose that such studies in multivariate regression can straightforwardly dissect out the supposed opiate attributable cardiovascular risk. Other factors, such as HDL and CRP, remained in the model, and were included in many interactive terms. Yet, the literature strongly indicates that such factors themselves may be perturbed by opiate dependence acting by multiple pathophysiological pathways, which is therefore likely acting by multiple pathways as discussed below. Furthermore, since opiate receptors and endorphins play a central role in appetitive regulation, it is likely that even factors such as tobacco and other substance use are also impinged upon by the hypothalamic effects of opiates. ${ }^{30}$ Hence, it is likely that 
Table 4 Final model of cardiovascular risk factors

\begin{tabular}{|c|c|c|c|}
\hline \multirow[t]{2}{*}{ Variable } & \multicolumn{3}{|c|}{ Parameter estimates } \\
\hline & Estimate (SEM) & $t$ value & $P(>t)$ \\
\hline $\mathrm{CA}$ & $1.4963(0.2968)$ & 5.042 & 0.000001 \\
\hline Cigarettes & $0.5215(0.1126)$ & 4.632 & 0.000006 \\
\hline H.Dose:H.Dura.n:Cigarettes & $0.0845(0.0168)$ & 5.014 & 0.000001 \\
\hline H.Dose:Cigarettes:HDL & $-0.2142(0.0429)$ & -4.997 & $0.00000 \mathrm{I}$ \\
\hline CA:H.Dose:H. & $-0.0231(0.0046)$ & -4.995 & 0.000001 \\
\hline \multicolumn{4}{|l|}{ Dura.n:Cigarettes } \\
\hline H.Dose:H. & $-0.0398(0.0082)$ & -4.876 & 0.000002 \\
\hline \multicolumn{4}{|l|}{ Dura.n:Cigarettes:CRP } \\
\hline CA:H.Dose:H. & $0.0109(0.0022)$ & 4.844 & 0.000002 \\
\hline \multicolumn{4}{|l|}{ Dura.n:Cigarettes:CRP } \\
\hline CA:H. & $-0.0139(0.003)$ & -4.695 & 0.000004 \\
\hline \multicolumn{4}{|l|}{ Dura.n:Cigarettes:HDL:CRP } \\
\hline CA:Cigarettes & $-0.15(0.0323)$ & -4.639 & 0.000006 \\
\hline CA:H.Dose:H.Dura.n:HDL:CRP & $-0.0361(0.008)$ & -4.541 & 0.000009 \\
\hline CA:H & $0.0017(0.0004)$ & 4.426 & 0.000015 \\
\hline \multicolumn{4}{|l|}{ Dura.n:Cigarettes:HDL:CRP } \\
\hline H.Dura.n:Cigarettes:HDL:CRP & $0.0468(0.0107)$ & 4.379 & 0.000018 \\
\hline H.Dura.n:Cigarettes & $-0.0173(0.0043)$ & -4.017 & 0.000079 \\
\hline CA:H.Dura.n:Cigarettes & $0.0046(0.0012)$ & 3.985 & 0.000090 \\
\hline H.Dose:Cigarettes & $-0.8874(0.2289)$ & -3.877 & 0.000136 \\
\hline CA:H.Dose:Cigarettes & $0.2633(0.0685)$ & 3.845 & 0.000155 \\
\hline CA:H.Dura.n:HDL:CRP & $0.1008(0.0276)$ & 3.654 & 0.000317 \\
\hline H.Dose:H.Dura.n:CRP & 0.403 I (0.1 I I27) & 3.576 & 0.000423 \\
\hline CA:H.Dose:H.Dura.n:CRP & $-0.107(0.0309)$ & -3.465 & 0.000629 \\
\hline CA:Cigarettes:CRP & $0.0342(0.0105)$ & 3.253 & 0.001304 \\
\hline CA:H.Dose:Cigarettes:CRP & $-0.0853(0.0265)$ & -3.215 & 0.001486 \\
\hline H.Dose:Cigarettes:CRP & $0.2847(0.0887)$ & 3.209 & 0.001512 \\
\hline H.Dura.n:HDL:CRP & $-0.3348(0.1043)$ & -3.209 & 0.001515 \\
\hline Cigarettes:CRP & $-0.1144(0.0363)$ & -3.153 & 0.001821 \\
\hline CA:H.Dura.n:Cigarettes:HDL & $0.0171(0.0056)$ & 3.047 & 0.002572 \\
\hline HDL & $-0.7057(0.2548)$ & -2.77 & 0.006044 \\
\hline H.Dura.n:Cigarettes:HDL & $-0.055 \mathrm{I}(0.0203)$ & $-2.7 \mid$ & 0.007218 \\
\hline Height & $-0.0079(0.003)$ & -2.629 & 0.009106 \\
\hline H.Dose:HDL & $24.4529(9.6589)$ & 2.532 & 0.011992 \\
\hline H.Dose:H.Dura.n & $-0.5804(0.2394)$ & -2.424 & 0.016075 \\
\hline CA:H.Dose:HDL:CRP & $2.7068(1.1502)$ & 2.353 & 0.019410 \\
\hline CA:H.Dose:H.Dura.n & $0.1518(0.0647)$ & 2.348 & 0.019712 \\
\hline CA:H.Dose:HDL & $-6.4165(2.7534)$ & -2.33 & 0.020614 \\
\hline H.Dose:HDL:CRP & $-8.4165(3.9594)$ & -2.126 & $0.03455 I$ \\
\hline
\end{tabular}

Abbreviations: CA, chronologic age; H.Dose, heroin dose; H.Dura.n, heroin duration; cigarettes, daily tobacco consumption as cigarettes/day; HDL, high density lipoprotein; LDL, low density lipoprotein; SEM, standard error of the mean; CRP, C-reactive protein.

opiates are acting by multiple routes, many of which are included under various terms in regression models, beyond simply those directly associated with opiate use itself.

Other researchers have also noted the increased rate of cardiovascular disease in opiate dependence, particularly where such patients are treated with methadone. ${ }^{31}$ One large Californian study found an increased incidence of hypertension in these patients. ${ }^{28} \mathrm{~A}$ careful angiographic study found elevated rates, severity, and premature occurrence of clinically significant coronary disease requiring open vascular reconstruction. ${ }^{32}$ Researchers in Sydney have identified a greatly elevated risk of cardiovascular disorders in these patients when reviewing a large state wide methadone program with a relative risk of 2.2 (95\% confidence interval 1.8-2.5). ${ }^{33}$ They have also shown that $17 \%$ of these patients over the age of 44 years have coronary stenoses exceeding $75 \%$, together with other cardiac pathologies including interstitial fibrosis, ${ }^{5}$ and that these changes are worse in methadone treated patients. ${ }^{4}$ There is further literature showing exacerbation of all cardiovascular risk factors by long-term opiate dependence. Hence, there is a body of evidence, which overall is compelling, that shows a real association between cardiovascular disease and opiate dependence, although it appears to not be well understood at the mechanistic level.

These findings raise the question as to the likely mechanism of the observed effects. While opiates have effects in many systems, several in particular would appear to be relevant to their pro-aging activities. En passant, it is worth noting that these effects have occurred despite better total cholesterol and low density lipoprotein data in the drug dependent group (Table 1) and despite their significantly older CA. Hence, the beneficial effects of an improved lipid profile in these patients appear to have been overcome by other factors. The direct effects on the P16 system were outlined in some detail in the Introduction section. Opiates have been shown to impair stem cell number ${ }^{34}$ and activity, ${ }^{35}$ acting through Akt and cyclindependent kinase 5, as well as P16INK4A. ${ }^{9}$ P16 has also been shown to induce senescence directly. ${ }^{36}$ Opiates have also been shown to either cause or potentiate cellular apoptosis, ${ }^{37}$ a change likely to be exacerbated by the reduction in replacement from the progenitor cell pool. Opiates also bind directly to toll-like receptor 4 and various chemokines, and directly trigger the pro-inflammatory pathways signaling to nuclear factor- $\kappa \mathrm{B} .{ }^{38}$ Many stem cells are very sensitive to inflammatory cytokines and rapidly shut down replicative activity. ${ }^{39}$ Moreover, an increase in these various pro-senescence changes will increase the likelihood of various tissues entering senescence. Senescent tissues have themselves been shown to release pro-inflammatory cytokines such as interleukins- 6 and -8 , which at once feed forward and magnify the pro-inflammatory, prosenescence response, further suppressing cell replication and renewal. ${ }^{40}$

As noted earlier, it is likely that cardiovascular aging is a useful surrogate marker for general aging across the whole of the organism. ${ }^{22}$ Certainly, tabulations demonstrating significantly elevated rates of morbidity and mortality 
in opiate dependence across all body tissues, such as that recently published from a large state wide program in Sydney, that show elevated rates of disease and dysfunction in essentially all body systems strongly support such a view. ${ }^{33}$ They are also consistent with other studies documenting age related changes in opiate dependence in teeth, bone density, and hair greying, and with reduction in stem cell numbers. ${ }^{34,41-43}$

There are several limitations of this study. Formal taking of the drug history in a form which allowed ready data analysis would have been an advantage, and should be considered in any future replication of this work. The composition of the study population has been mentioned as an issue, and it would therefore be useful in any future sample of opiate dependent patients to give careful thought to deliberate sampling of opiate dependent populations treated with various agents. A further useful refinement would be to follow patients sequentially to determine if their indices of vascular aging vary with their treatment type, or with periods of drug free rehabilitation. In making these suggestions, this is not to minimize the very real difficulties experienced by most research groups in tracking opiate dependent patients. It would also be useful to randomize patients to treatments at the outset, thereby controlling baseline variables. The lack of control in our study environment of factors such as food, drink, exercise, and tobacco consumption prior to the performance of the pulse wave tonometry studies is also a shortcoming. It would also be of interest to follow various markers of cellular and cytokine senescence in these patients.

In summary, the present work has shown a dose response effect of lifetime opiate exposure with central cardiovascular age and measures of arterial stiffness, demonstrated elevated levels of arterial stiffness in opiate dependence, and shown that the effect of opiates on central VA persist even in models including other major cardiovascular risk factors. There is a broad base of molecular and cellular aging and senescence theory to explain such changes. This body of work is consistent with prior survey, postmortem, population based, and angiographic studies which also document elevated rates of coronary disease in opiate dependence. As such, it is suggested that opiate dependence forms a complex but important model to study coronary atherogenesis. These findings also form an important surrogate marker for accelerated aging of the whole organism. Various suggestions are made for refinements of these findings in future studies.

\section{Acknowledgment}

The authors would like to thank Dr Mervyn Thomas of Emphron for assistance with the statistics and graphical design.

\section{Disclosure}

The authors report no conflict of interest in this work. This work is the work of the authors in its entirety.

\section{References}

1. Gottshcalk LA, McGuire FL, Heiser JF, Dinovo EC, Birch H. Drug Abuse Deaths In Nine Cities: A Survey Report. Rockville: National Institute of Drug Abuse; 1979.

2. Cami J, Farre M. Drug addiction. N Engl J Med. 2003;349(10): 975-986.

3. Darke S, Degenhardt L, Mattick R. Mortality Amongst Illicit Drug Users: Epidemiology, Causes And Intervention. Sydney: Cambridge University Press; 2006.

4. Darke S, Duflou J, Torok M. The comparative toxicology and major organ pathology of fatal methadone and heroin toxicity cases. Drug Alcohol Depend. 2010;106(1):1-6.

5. Darke S, Kaye S, Duflou J. Systemic disease among cases of fatal opioid toxicity. Addiction. 2006;101(9):1299-1305.

6. Hulse G, White J, Cape G, editors. Management of Drug and Alcohol Problems. Sydney: Oxford University Press; 2002.

7. Oviedo-Joekes E, Brissette S, Marsh DC, et al. Diacetylmorphine versus methadone for the treatment of opioid addiction. $N$ Engl J Med. 2009;361(8):777-786.

8. McLaughlin PJ, Zagon IS, White WJ. Perinatal methadone exposure in rats. Effects on body and organ development. Biol Neonate. 1978;34(1-2):48-54.

9. Zagon IS, Verderame MF, McLaughlin PJ. The biology of the opioid growth factor receptor (OGFr). Brain Res Brain Res Rev. 2002;38(3): 351-376.

10. Cheng F, McLaughlin PJ, Verderame MF, Zagon IS. The OGF-OGFr axis utilizes the p16INK4a and p21 WAF1/CIP1 pathways to restrict normal cell proliferation. Mol Biol Cell. 2009;20(1):319-327.

11. Feero WG, Guttmacher AE, McCarthy MI. Genomics, type 2 diabetes, and obesity. N Engl J Med. 2010;363(24):2339-2350.

12. O'Donnell CJ, Nabel EG. Genomics of cardiovascular disease. $N$ Engl J Med. 2011;365(22):2098-2109.

13. Visel A, Zhu Y, May D, et al. Targeted deletion of the 9p21 noncoding coronary artery disease risk interval in mice. Nature. 2010; 464(7287):409-412.

14. Harismendy O, Notani D, Song X, et al. 9p21 DNA variants associated with coronary artery disease impair interferon-gamma signalling response. Nature. 2011;470(7333):264-268.

15. Pasmant E, Sabbagh A, Vidaud M, Bieche I. ANRIL, a long, noncoding RNA, is an unexpected major hotspot in GWAS. FASEB J. 2010;25(2): 444-448.

16. Jamison RN, Serraillier J, Michna E. Assessment and treatment of abuse risk in opioid prescribing for chronic pain. Pain Res Treat. 2011;2011:941808.

17. US Department of Health and Human Services, Substance Abuse And Mental Health Services Administration, Office of Applied Studies. Drug Abuse Warning Network (DAWN), Treatment Episode Data Set - Admissions (Teds-A) - Concatenated, 1992 to 2009 [Computer file]. Prepared by Synectics for Management Decisions, Incorporated. ICPSR25221-v4. 2011;1. Available from http://www.samhsa.gov/data/ DASIS.aspx?qr=t\#TEDS. Accessed December 28, 2011.

18. Verbeke F, Marechal C, Van Laecke S, et al. Aortic stiffness and central wave reflections predict outcome in renal transplant recipients. Hypertension. 2011;58(5):833-838. 
19. Van Bortel LM, Duprez D, Starmans-Kool MJ, et al. Clinical applications of arterial stiffness, Task Force III: recommendations for user procedures. Am J Hypertens. 2002;15(5):445-452.

20. Nichols WW. Clinical measurement of arterial stiffness obtained from noninvasive pressure waveforms. Am J Hypertens. 2005;18(1 Pt 2): 3S-10S.

21. Nichols WW. McDonald's Blood Flow in Arteries: Theoretical, Experimental and Clinical Principles. Nichols WW, O'Rourke MF, editors. London: Hodder Arnold; 2005.

22. Chien KR, Karsenty G. Longevity and lineages: toward the integrative biology of degenerative diseases in heart, muscle, and bone. Cell. 2005;120(4):533-544.

23. Opiate exposure increases arterial stiffness, advances vascular age and is an independent cardiovascular risk ractor in females: a cross-sectional clinical study. World J. Cardiovascular Diseases. In Press.

24. Reece AS, Hulse GK. Impact of opioid pharmacotherapy on arterial stiffness and vascular ageing: cross-sectional and longitudinal studies. Cardiovasc Toxicol. Epub March 3, 2013.

25. Reece AS, Hulse GK. Reduction in arterial stiffness and vascular age by naltrexone-induced interruption of opiate agonism. BMJ Open. 2013;3(3):e002610.

26. Reece AS. Psychosocial and treatment correlates of opiate free success in a clinical review of a naltrexone implant program. Subst Abuse Treat Prev Policy. 2007;2:35.

27. Reece AS. Evidence of accelerated ageing in clinical drug addiction from immune, hepatic and metabolic biomarkers. Immun Ageing. 2007;4:6.

28. Hser YI, Gelberg L, Hoffman V, Grella CE, McCarthy W, Anglin MD. Health conditions among aging narcotics addicts: medical examination results. J Behav Med. 2004;27(6):607-622.

29. Randall D, Degenhardt L, Vajdic CM, et al. Increasing cancer mortality among opioid-dependent persons in Australia: a new public health challenge for a disadvantaged population. Aust $N$ Z J Public Health. 2011;35(3):220-225.

30. Reece AS. Hypothalamic opioid-melanocortin appetitive balance and addictive craving. Med Hypotheses. 2011;76(1):132-137.

31. Rosen D, Smith ML, Reynolds CF 3rd. The prevalence of mental and physical health disorders among older methadone patients. Am J Geriatr Psychiatry. 2008;16(6):488-497.
32. Sadeghian S, Darvish S, Davoodi G, et al. The association of opium with coronary artery disease. Eur J Cardiovasc Prev Rehabil. 2007; 14(5):715-717.

33. Degenhardt L, Randall D, Hall W, Law M, Butler T, Burns L. Mortality among clients of a state-wide opioid pharmacotherapy program over 20 years: risk factors and lives saved. Drug Alcohol Depend. 2009; 105(1-2):9-15.

34. Reece AS, Davidson P. Deficit of circulating stem - progenitor cells in opiate addiction: a pilot study. Subst Abuse Treat Prev Policy. 2007;2:19.

35. Russo SJ, Bolanos CA, Theobald DE, et al. IRS2-Akt pathway in midbrain dopamine neurons regulates behavioral and cellular responses to opiates. Nat Neurosci. 2007;10(1):93-99.

36. Coppe JP, Rodier F, Patil CK, Freund A, Desprez PY, Campisi J. Tumor suppressor and aging biomarker p16(INK4a) induces cellular senescence without the associated inflammatory secretory phenotype. J Biol Chem. 2011;286(42):36396-36403.

37. Cunha-Oliveira T, Rego AC, Garrido J, Borges F, Macedo T, Oliveira CR. Street heroin induces mitochondrial dysfunction and apoptosis in rat cortical neurons. J Neurochem. 2007;101(2):543-554.

38. Hutchinson MR, Zhang Y, Shridhar M, et al. Evidence that opioids may have toll-like receptor 4 and MD-2 effects. Brain Behav Immun 2010;24(1):83-95.

39. Anderson JE. A role for nitric oxide in muscle repair: nitric oxidemediated activation of muscle satellite cells. Mol Biol Cell. 2000;11(5): 1859-1874.

40. Bhaumik D, Scott GK, Schokrpur S, et al. MicroRNAs miR-146a/b negatively modulate the senescence-associated inflammatory mediators IL-6 and IL-8. Aging (Albany NY). 2009;1(4):402-411.

41. Reece AS. Dentition of addiction in Queensland: poor dental status and major contributing drugs. Aust Dent J. 2007;52(2):144-149.

42. Reece AS. Hair graying in substance addiction. Arch Dermatol. 2007;143(1):116-118.

43. Kim TW, Alford DP, Malabanan A, Holick MF, Samet JH. Low bone density in patients receiving methadone maintenance treatment. Drug Alcohol Depend. 2006;85(3):258-262.
Vascular Health and Risk Management

\section{Publish your work in this journal}

Vascular Health and Risk Management is an international, peerreviewed journal of therapeutics and risk management, focusing on concise rapid reporting of clinical studies on the processes involved in the maintenance of vascular health; the monitoring, prevention and treatment of vascular disease and its sequelae; and the involvement of

\section{Dovepress}

metabolic disorders, particularly diabetes. This journal is indexed on PubMed Central and MedLine. The manuscript management system is completely online and includes a very quick and fair peer-review system, which is all easy to use. Visit http://www.dovepress.com/ testimonials.php to read real quotes from published authors. 